laboratories and institute surveys, which may discover and provide beforehand for the needs of a growing population.

The chemist and geologist have their high and appointed vocation as much as priest or politician. A Franklin, who turns away from the splendor of courts to perfect electrical machines, and a Faraday, who put away from him during the course of a lifetime a quarter of a million of pounds sterling, and preferred the public good to riches, are not the least noble of those who say "the common wealth is their greatest wealth, the public weal their highest good."

Perhaps there are some here who will have an instrumentality in solving some of the problems which I have brought before you to-night-some who may make the glorious discovery that these foundation stones of Eastern Pennsylvania, those which we have so often tramped over before, looking only for the minerals they contain, are not Azoic, but have once been peopled with life. To bring into order what has hitherto baffled the knowledge of geolo. gists, to show precisely of what age these rocks are, and, if possible, to detect the broken and confused relics of crab and shell which they may contain, I solicit the help and study of every young student in my audience. And to encourage and stimulate us by your interest and sympathy, to found for us laboratories wherein we may successfully examine the material that we have gathered from the fields or dug from beneath the hills, I turn to you, my older friends and much valued fellow-members of the Institute.

\title{
ON A NEW CONNECTION FOR THE INDUCTION COIL.
}

By Prof. Edwin J. Houston.

1 The following experiments were made at the Central High School of Philadelphia, with the view of increasing the quantity of the spark of the induction coil without greatly diminishing its length. The instrument used was made by Ritchie, of Boston, and will throw the spark six inches in free air.

One of the poles or ends of the secondary wire was connected with the earth by a copper wire attached to a gas pipe. The other pole was connected with a wire, which rested on a large lecture table holding the coil. On turning the break piece, the electricity, instead of being lost by passing along the wires to the earth, jumped

Vol. LXI.-Third Series. - No. 6. July, 1871. 
from the pole connected with the table, to that connected with the earth. The thickness of the spark was greatly increased, its length diminished, and its color changed to a silvery white, as when a Teyden jar is placed in the path of the discharge.

While the electricity is flowing between the points, long sparks may be drawn from any part of the table, or from any metallic ar. ticle within eight or nine feet of the coil. On one occasion the gas was lighted by a spark drawn from the finger of a person standing on the floor. The gas pipe being in almost perfect connection with the earth, the spark must have been given to it from the body of the person.

On another occasion one wire was attached to the gas pipe as before, and the other to a stove, whose pipe connects with that of another stove in an adjoining room. The thickness of the spark was greatly increased. Sparks were drawn from the distant stove, and even from a small steam engine, which latter was fully thirty feet from the coil. In all the experiments it was found necessary to insulate the handle of the break piece, as a slight shock was experienced at every break. The poles being kept at a distance from each other less than the insulating power of the coil, six inches, no danger of injuring the instrument was apprehended. In one instance sparks were drawn, in a room underneath the adjoining room, from a wire which connected with the table on which the coil rested.

These facts showing great loss of the electricity, but indicating the need for a large conductor, probably to allow the rapid discharge of the secondary wire, a large insulated conductor was extemporized by placing some old tin stills and percolators on large glass jars. On connecting one of the poles with this conductor, and the other with the gas pipe, the quantity of the spark was increased, though there was reason to believe that, with a larger conductor, better results would have been obtained. The conductor was then divided into two, of about equal size, which were connected with the poles. The quantity of the spark was increased, with, however, great diminution in the length. By successively diminishing the size of one of the conductors, and increasing that of the other, the length of the spark was increased, without any sensible diminution in its quantity, until, when one of the conductors was less than one square foot in surface, a fine quantity spark of about five inches was obtained.

It will be noticed that this connection is somewhat similar to that used in the common cylinder or plate machine, in which one of the conductors, generally the negative, is connected with the earth, and the quantity of the electricity thereby increased. 
In all the experiments in which one pole was in partial connection with the earth, as when it rested on the table, the loss of electricity must have been very great, for several gas and water pipes are in connection with the table. If, then, the table merely serves as an imperfectly insulated conductor, which allows the rapid induction of electricity in the secondary wire by its rapid discharge, and thereby, notwithstanding the loss, gives so great an increase in the quantity of the spark, it would seem that if, instead of the table, an insulated conductor of very large surface were used, a much greater increase in quantity would be obtained.

It would seem from the above experiments that the maximum increase will be obtained when one of the poles is connected with an insulated conductor, say several hundred square feet in surface, and the other with the earth.

\section{ON THE USE OF HYDRAULIC MORTAR.}

[Translated from "Die hydraulischen Mörtel" of Dr. W. Michaelis, for the Journal of the Franklin Institute.]

By Adolph Otт.

(Continued from page 337.)

On the Preparation of the Mixture.

Is preparing hydraulic mortar, it is advisable to begin in mixing the dry lime or cement-powder with clean sand. When these form a thorough mixture, the requisite quantity of water must be gradually added under constant stirring up of the material. In no other way can a uniformly and evenly mixed mortar be obtained with rapidly binding lime or cement; while, if the lime or cement is first mixed with water, a partial binding and consequent clogging of the material takes place, which either precludes the possibility of a perfect and satisfactory mixture of the sand then added, or renders it at least extremely difficult.

It is self-understood that the water must be clean, that is to say, free from all such substances as may interfere with the adhesion of the particles, like clay, mud, grease and mucilaginous matter.

The mixture of water ought to be such as to secure a product of the most even consistency; this is no doubt obtained with less difficulty and more chance of success through the use of mortar. 